\title{
Satisfaction of a Saudi Population with their Smiles
}

\author{
Majed D Aldakheel ${ }^{1}$, May A Ahmed ${ }^{2 *}$ and Raneem I Alduraiby ${ }^{2}$ \\ ${ }^{1} A E G D, S B-R D S$, Head of Dental Department, King Abdulaziz University Hospital, Saudi Arabia \\ ${ }^{2} B D S$, Riyadh Colleges of Dentistry and Pharmacy, Saudi Arabia
}

Submission: December 21, 2016; Published: January 09, 2017

*Corresponding author: May A Ahmed, Riyadh Colleges of Dentistry and Pharmacy, Saudi Arabia, Tel: +966556779238;

Email: May.a.ahmed@hotmail.com

\section{Abstract}

Introduction: Dental esthetics has become a very important concern in daily life because it has a direct impact on self-confidence, selfesteem and quality of life. The aim of this study was to determine the self-evaluated smile satisfaction among a Saudi population and the desired treatment that they would like to undergo to improve their smiles.

Materials \& Methods: A survey study, which included 1129 participants, was performed to determine the self-evaluated smile satisfaction among the Saudi population and the treatments they hope for to improve their smiles.

Result: The 1129 participants consisted of 273 males (24.2\%) and 856 females (75.8\%), with a median age of 26-33 years. Of these participants, 434 (38.4\%) were not satisfied with their general dental appearance. In addition, 718 participants (63.6\%) were dissatisfied with the color of their teeth, 381 (33.7\%) reported that their teeth were poorly aligned or crowded and $337(29.8 \%)$ reported that their teeth protruded. Tooth whitening was the treatment most desired by participants (53.7\%), followed by orthodontic treatment (29.6\%).

Conclusion: High levels of dissatisfaction with participants' smile appearance and a higher level of tooth color dissatisfaction were reported in this study, which provide useful information about the potential needs for dental treatment, particularly esthetic treatment, including teeth whitening, orthodontic treatment and veneers. Moreover, understanding patients' perceptions of their smiles is an important aspect of good patient management that may help dentists to provide adequate and appropriate treatment plans for achieving a high level of patient satisfaction.

Keywords: Smile; Satisfaction; Tooth color; Esthetic

\section{Introduction}

As part of common sense, humans always look for the best, including the best in power, position or beauty. For a long time, the humans have looked for beauty in different ways, which depend on the cultural background and social class. In some prestigious professions, good dental appearance is thought to be a job requirement [1]. Functional demands were an essential consideration in dental treatment and recently, dental esthetic has become a very important concern in daily life [2,3] because it has a direct impact on self-confidence, self-esteem and the quality of life [4-7]. The concern about dental appearance has been noted in the last few decades and evolution in dentistry requires helping unsatisfied people with their specific problems.

The influence of facial features on the perception of attractiveness differs among individuals. Langlois and Roggman stated that "an average looking face is more beautiful" [8], and Tufekci et al. reported that "individuals who perceive their profiles as being different from average were found more likely to be dissatisfied with their facial appearance" [9]. As a part of the facial structure, dentition plays an important role in facial appearance because it is frequently concerned with dental arrangement, alignment and appearance $[10,11]$. The effect of a smile goes beyond the attractiveness of a face [12]. Indeed the tooth size, shape, position and visibility all play an important role in smile self-satisfaction because an imbalance in any of these factors will end up with dissatisfaction [13-15].

Furthermore, an esthetically pleasing smile is not restricted to tooth factors, such as the tooth color, size, shape, position and visibility. In fact, the lower half of the face is also an important factor in building up a pleasant smile; the smile is also affected by the curvature of the lips and amount of gingival display. They are all considered the frame of the smile and have a great impact on the smile $[14,16,17]$. Although each factor could be 
considered separately, all components must act together to produce a harmonic and balanced entity that will create the final esthetic effect [13-15].

Currently, esthetic dentistry has become a major aspect of dental practice, which could be explained by the greater understanding of smile perception, media and advertising, leading to a change in dental treatment priority $[2,18,19]$. People's eagerness for pearly white teeth shows that tooth color is an influential factor in determining satisfaction with dental appearance $[1,8]$. Tooth color was noticed to be the most important point of dissatisfaction in the UK [3], India [20], Turkey [21], Malaysia [15] and China (urban population) [22]. Tooth whitening treatments, anterior teeth restorations, labial veneers, crowns, orthodontic treatments, periodontal surgeries and lip fillers are all frequently demanded by individuals who seek to improve their smiles $[2,15]$. To address these demands, dental practitioners should be more aware of patients' dental needs when planning treatments [23].

Currently, many efforts are made in designing a smile analysis protocol to have a starting point in building a better smile. Many smile analysis forms have been made which need time and effort to establish a treatment plan for a better smile. Still, to date there is no digital smile analysis form that fulfills these needs to gain a faster and more accurate analysis, making this issue an important aspect for future innovations. However, smile satisfaction within the Saudi population is not well known, and there is a lack of information on that topic, which raises the need to record that satisfaction and the most commonly requested esthetic treatments. The aim of this study was to determine the self-evaluated smile satisfaction among a Saudi population and the desired treatment that they would like to undergo to improve their smiles.

\section{Materials and Methods}

This study was conducted from June to August 2015. One thousand one hundred and twenty-nine participants were included in this study (273 male and 856 female). Their ages ranged from 18 to 41 years old. For inclusion in the study, participants had to be 18 years old or older to understand and score the questionnaire. A brief explanation of the study was included at the beginning of the questionnaire before participants answered the questions.

A structured questionnaire was distributed through social media to determine participants' satisfaction with their smiles and what treatments they desired to undergo to improve their esthetics. The questionnaire was adopted from previous studies, which found it valid and reliable [15,23]. The questionnaire included items on the socio demographic data (such as; age (1825, 26-33, 34-41 years), gender, and level of education (high school or lower, Bachelor's degree, Postgraduate or higher), tooth color, tooth alignment and tooth position). Additionally, the questionnaire included items that inquired about the presence of caries, tooth-colored fillings and tooth fractures.
Furthermore, the questionnaire included items that attempted to identify whether participants desired treatment to improve their appearance; such treatments included orthodontics, tooth whitening, veneers or lumineers, dental crowns, tooth-colored fillings and dentures. Moreover, the questionnaire included a visual analogue scale (VAS) for the participants to score their level of satisfaction with their smiles. The VAS ranged from zero to ten, where zero indicates the lowest satisfaction with the smile appearance and ten indicates the maximum satisfaction with the smile appearance.

The questionnaire was modified for this study by including items that tackle patients' satisfactions with their smiles; these items were the number of teeth displayed during smiling, color of the gingiva, amount of gingival displayed during smile, lip position during smiling and veneers or lumineers as a treatment option. The questionnaire was conducted through a google form, and the link was distributed through social media. Each participant was allowed to answer the questionnaire only once.

The English version of the questionnaire was translated into the Arabic language by three experts and fluent bilingual individuals, and it was then translated back into English by another three individuals who were fluent in Arabic and English. Modifications to the questionnaire were made as necessary to ensure comprehension. Twenty individuals were asked to score the English format of the questionnaire and were then asked to score the translated Arabic version. The answers of the two formats of the questionnaire were compared using the t-test, and no statistically significant differences were found. The data obtained from the above procedure were not included in the main study. Twenty participants answered the Arabic questionnaire twice with a five-day interval. A reliability test was performed on all questions using correlation coefficients. The association coefficients were high (0.96). Then, the final version of the questionnaire was distributed to the participants in the main study sample.

The data were entered into the computer and analyzed using the SPSS computer software (Statistical Package for the Social Sciences, version 19.0, SPSS Inc., Chicago, IL, USA). First, descriptive statistics were performed to present the overview of the findings. Then, the association between the variables was analyzed using the Mann Whitney U test, while the Kruskal Wallis $\mathrm{H}$ test was used to compare satisfied and dissatisfied patients. Fisher's exact and Pearson Chi-square tests were used to determine the association between the categorical variables. For all statistical analysis, the significance level was set at $\mathrm{p} \leq$ 0.05 . The sample has a power of $90 \%(n=1129)$.

\section{Results}

In total, 1129 participants (24.2\% male and $75.8 \%$ female) were involved in this study. Their ages ranged from 18 to 41 years old (18-25, 26-33, 34-41 years; the median age was 2633 years). The participants' level of education was as follows: high school or lower (13.7\%), Bachelor's degree (73.1\%), and 


\section{Advances in Dentistry \& Oral Health}

Postgraduate or higher (13.2\%) (Table 1).There was a nonsignificant association between demographic factors (age and gender) and satisfaction with the smile. However, significant

Table 1: Sociodemographic Background of Participants' who were $(\mathrm{N}=695)$ and were Not $(\mathrm{N}=434)$ Satisfied with their Smiles.

\begin{tabular}{|c|c|c|c|c|c|}
\hline \multicolumn{2}{|r|}{ Items } & $\begin{array}{l}\text { Participant number } \\
\left(n^{*}=1129\right)(\%) \text { Item }\end{array}$ & $\begin{array}{c}\text { Satisfied group } n= \\
695(\%)\end{array}$ & $\begin{array}{l}\text { Dissatisfied group } n \\
\quad=434(\%)\end{array}$ & $p$ value \\
\hline \multirow{3}{*}{ Age } & 18 to 25 & $517(45.8 \%)$ & $331(47.6 \%)$ & $186(42.9 \%)$ & \multirow{3}{*}{$P=0.115$} \\
\hline & 26 to 33 & $363(32.2 \%)$ & $224(32.3 \%)$ & $139(32 \%)$ & \\
\hline & 34 to 41 & $249(22.2 \%)$ & $140(20.1 \%)$ & $109(25.1 \%)$ & \\
\hline \multirow{2}{*}{ Gender } & Female & $856(75.8 \%)$ & $532(76.5 \%)$ & $324(74.7 \%)$ & \multirow{3}{*}{$P=0.476$} \\
\hline & Male & $273(24.2 \%)$ & $163(23.5 \%)$ & $110(25.3 \%)$ & \\
\hline \multirow{3}{*}{ Level of Education } & High school or lower & $155(13.7 \%)$ & $72(10.4 \%)$ & $83(19.1 \%)$ & \\
\hline & Bachelor's degree & $825(73.1 \%)$ & $524(75.4 \%)$ & $301(69.4 \%)$ & \multirow{2}{*}{$P=0.000$} \\
\hline & Post graduated or higher & $149(13.2 \%)$ & $99(14.2 \%)$ & $50(11.5 \%)$ & \\
\hline
\end{tabular}

Table 2: Distribution of the Study Sample by their Answers to the Questionnaire Items.

\begin{tabular}{|c|c|c|}
\hline \multirow{2}{*}{ Item } & \multicolumn{2}{|c|}{ Participants' Answers (n* =1129) (100\%) } \\
\cline { 2 - 3 } Yes (\%) & No (\%) & $434(38.4 \%)$ \\
\hline satisfied with their smile & $695(61.1 \%)$ & $718(63.6 \%)$ \\
\hline satisfied with their tooth color & $411(36.4 \%)$ & $748(66.3 \%)$ \\
\hline feeling their teeth are crowded or poorly aligned & $381(33.7 \%))$ & $792(70.2 \%)$ \\
\hline feeling their teeth are protruded & $336(29.8 \%)$ & $810(71.7 \%)$ \\
\hline have dental caries or non-aesthetic fillings in their frontal teeth & $319(28.3 \%)$ & $950(84.1 \%)$ \\
\hline have fractures in their frontal teeth & $179(15.9 \%)$ & $215(19.1 \%)$ \\
\hline satisfied with the number of teeth displayed during smiling & $914(80.9 \%)$ & $295(26.1 \%)$ \\
\hline satisfied with the color of your gingiva & $834(73.9 \%)$ & $241(21.7 \%)$ \\
\hline satisfied with the amount of gingival displayed during smiling & $885(78.7 \%)$ & $253(22.4 \%)$ \\
\hline satisfied with the lip position during smiling & $876(77.6 \%)$ & \\
\hline
\end{tabular}

There was a significant association $(\mathrm{P}=0.000)$ between the answers to the questionnaire items and participant satisfaction. Participants had dissatisfaction of $51.2 \%$ with the color of their teeth despite satisfaction with their smile. Furthermore, $43.3 \%$ lacked crowding or poorly aligned teeth, $55.1 \%$ did not feel that their teeth were protruded, $72.4 \%$ had an appropriate tooth size, $56.2 \%$ did not report caries or non-esthetic filling

\begin{tabular}{|c|c|c|c|c|}
\hline Questions & Answer & $\begin{array}{l}\text { Satisfied with their } \\
\text { smile } n=695(\%)\end{array}$ & $\begin{array}{l}\text { Dissatisfied with their } \\
\text { smile } n=434(\%)\end{array}$ & pvalue \\
\hline \multirow{2}{*}{ 1- Are you satisfied with your tooth color? } & Yes & $339(48.8 \%)$ & $72(16.6 \%)$ & \multirow{2}{*}{$P=0.000$} \\
\hline & No & $356(51.2 \%)$ & $362(83.4 \%)$ & \\
\hline $\begin{array}{l}\text { 2- Do you feel your teeth are crowded or poorly } \\
\text { aligned? }\end{array}$ & Yes & $135(19.4 \%)$ & $246(56.7 \%)$ & $P=0.000$ \\
\hline
\end{tabular}




\section{Advances in Dentistry \& Oral Health}

\begin{tabular}{|c|c|c|c|c|}
\hline & No & $560(80.6 \%)$ & $188(43.3 \%)$ & \\
\hline \multirow{2}{*}{ 3- Do you feel your teeth are protruded? } & Yes & $142(20.4 \%)$ & $195(44.9 \%)$ & \multirow{2}{*}{$P=0.000$} \\
\hline & No & $553(79.6 \%)$ & $239(55.1 \%)$ & \\
\hline \multirow{3}{*}{ 4- Do you think your tooth size is } & Small & $21(3 \%)$ & $40(9.2 \%)$ & \multirow{3}{*}{$\mathrm{P}=0.000$} \\
\hline & Appropriate & $627(90.2 \%)$ & $314(72.4 \%)$ & \\
\hline & Big & $47(6.8 \%)$ & $80(18.4 \%)$ & \\
\hline \multirow{2}{*}{$\begin{array}{l}\text { 5- Do you have dental caries or non-aesthetic } \\
\text { filling in your frontal teeth? }\end{array}$} & Yes & $129(18.6 \%)$ & 190 (43.8\%) & \multirow{2}{*}{$\mathrm{P}=0.000$} \\
\hline & No & $566(81.4 \%)$ & $244(56.2 \%)$ & \\
\hline \multirow{2}{*}{ 6- Do you have fractures in your frontal teeth? } & Yes & $80(11.5 \%)$ & $99(22.8 \%)$ & \multirow{2}{*}{$\mathrm{P}=0.000$} \\
\hline & No & $615(88.5 \%)$ & $335(77.2 \%)$ & \\
\hline \multirow{2}{*}{$\begin{array}{l}\text { 7- Are you satisfied with the number of teeth } \\
\text { displayed during smiling? }\end{array}$} & Yes & $629(90.5 \%)$ & $284(65.4 \%)$ & \multirow{2}{*}{$\mathrm{P}=0.000$} \\
\hline & No & $66(9.5 \%)$ & $150(34.6 \%)$ & \\
\hline \multirow{2}{*}{$\begin{array}{l}\text { 8- Are you satisfied with the color of your } \\
\text { gingiva? }\end{array}$} & Yes & $549(79 \%)$ & 285 (65.7\%) & \multirow{2}{*}{$\mathrm{P}=0.000$} \\
\hline & No & $146(21 \%)$ & 149 (34.3\%) & \\
\hline \multirow{2}{*}{$\begin{array}{l}\text { 9- Are you satisfied with the amount of gingiva } \\
\text { displayed during smiling? }\end{array}$} & Yes & $581(83.6 \%)$ & $307(70.7 \%)$ & \multirow{2}{*}{$\mathrm{P}=0.000$} \\
\hline & No & $114(16.6 \%)$ & 127 (29.3\%) & \\
\hline \multirow{2}{*}{$\begin{array}{l}\text { 10- Are you satisfied with your lip position } \\
\text { during smiling? }\end{array}$} & Yes & $590(84.9 \%)$ & 286 (65.9\%) & \multirow{2}{*}{$P=0.000$} \\
\hline & No & $105(15.1 \%)$ & 148 (34.1\%) & \\
\hline
\end{tabular}

More than half of the participants (53.7\%) chose to undergo teeth whitening as a treatment to improve their smiles, which was followed by orthodontic treatment $(29.6 \%)$, veneers or lumineers (19.8\%), participants who were unwilling to undergo any treatment (17.5\%), participants who chose tooth colored fillings as a treatment (17.2\%), participants who wanted dental crowns (11.9\%), and $2 \%$ who chose dentures as treatment (Table 4).

Table 4: Participants' Desired Dental Treatment with their Smile Satisfaction (N=1129).

\begin{tabular}{|c|c|c|c|c|c|c|}
\hline Items & Treatment Options & $\begin{array}{c}\text { Participants' } \\
\text { Number } \\
\left(n^{*}=1129\right) \\
(100 \%)\end{array}$ & Answers & $\begin{array}{c}\text { Satisfied group } n \\
=695(\%)\end{array}$ & $\begin{array}{c}\text { Dissatisfied } \\
\text { group } n=434 \\
(\%)\end{array}$ & $p$ value \\
\hline \multirow{8}{*}{$\begin{array}{l}\text { Treatments } \\
\text { may undergo to } \\
\text { improve your } \\
\text { smile }\end{array}$} & \multirow{2}{*}{$\begin{array}{l}\text { Orthodontic } \\
\text { treatment to realign } \\
\text { teeth }\end{array}$} & \multirow{2}{*}{331 (29.6\%) } & Yes & $206(29.9 \%)$ & 125 (28.9\%) & \multirow{2}{*}{$P=737$} \\
\hline & & & No & $483(70.1 \%)$ & 308 (71.1\%) & \\
\hline & \multirow{2}{*}{ Tooth whitening } & \multirow{2}{*}{$601(53.7 \%)$} & Yes & $371(53.8 \%)$ & $230(53.1 \%)$ & \multirow{2}{*}{$\mathrm{P}=854$} \\
\hline & & & No & $318(46.2 \%)$ & 203 (46.9\%) & \\
\hline & \multirow{2}{*}{$\begin{array}{l}\text { Veneers or } \\
\text { Lumineers }\end{array}$} & \multirow{2}{*}{$222(19.8 \%)$} & Yes & 135 (19.6\%) & $87(20.1 \%)$ & \multirow{2}{*}{$\mathrm{P}=878$} \\
\hline & & & No & $554(80.4 \%)$ & $346(79.9 \%)$ & \\
\hline & \multirow{2}{*}{ Dental crown } & \multirow{2}{*}{$133(11.9 \%)$} & Yes & $80(11.6 \%)$ & $53(12.2 \%)$ & \multirow{2}{*}{$P=776$} \\
\hline & & & No & $609(88.4 \%)$ & $380(87.8 \%)$ & \\
\hline & Tooth-colored fillings & $193(17.2 \%)$ & Yes & $120(17.4 \%)$ & $73(16.9 \%)$ & $\mathrm{P}=871$ \\
\hline
\end{tabular}




\section{Advances in Dentistry \& Oral Health}

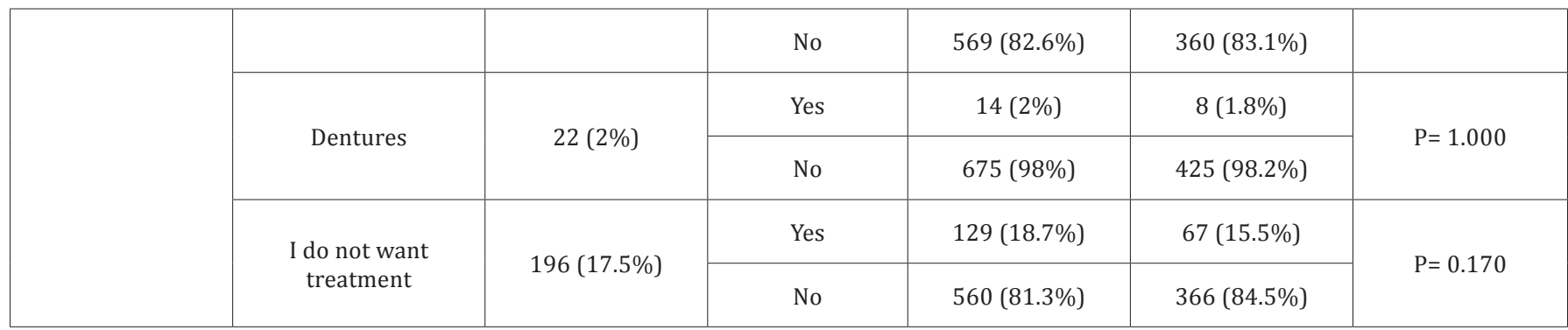

Simple logistic regression analysis of factors influencing participants' satisfaction with their smile demonstrated that there was no significant association between participants' satisfaction and the chosen treatment option. In this study, $53.1 \%$ of the participants chose to undergo tooth whitening, 28.9\% were willing to go thorough orthodontic treatment, $20.1 \%$ wanted veneers or lumineers, $16.9 \%$ wanted tooth colored fillings as a treatment and $12.2 \%$ chose dental crowns although all showed dissatisfaction with their smiles (Table 4).

Table 5: Background of Participants Who Had Crowding With Their Satisfaction of Tooth Color.

\begin{tabular}{|c|c|c|c|c|}
\hline \multirow{2}{*}{\multicolumn{2}{|c|}{ Question }} & \multicolumn{2}{|c|}{ Do you feel your teeth are crowded or poorly aligned? } & \multirow{2}{*}{$p$ value } \\
\hline & & Yes $(n=381)$ & No $(n=748)$ & \\
\hline \multirow{2}{*}{$\begin{array}{l}\text { Are you satisfied with your tooth } \\
\text { color? }\end{array}$} & Yes $(n=411)$ & $98(23.8 \%)$ & $313(76.2 \%)$ & \multirow{2}{*}{$\mathrm{P}=0.000$} \\
\hline & No $(n=718)$ & $283(39.4 \%)$ & $435(60.6 \%)$ & \\
\hline
\end{tabular}

Table 5 reveals that there is a significant association $(\mathrm{P}=0.000)$ when comparing between the number of participants who were dissatisfied with their tooth color and had crowding. Only 97 (8.6\%) were completely satisfied with their smiles and scored 10. Meanwhile, 21 (1.9\%) were not completely satisfied and scored 0 on the VAS. Furthermore, 864 (76.5\%) of the participants scored 5 or more with a mean score of 6.418 (Table 6).

Table 6: Distribution of the Satisfaction Score among the Study Population $(\mathrm{N}=1129)$.

\begin{tabular}{|c|c|c|c|c|}
\hline $\begin{array}{l}\text { Frequency of } \\
\text { participants }\end{array}$ & $\begin{array}{c}\text { Frequency of } \\
\text { participants }\end{array}$ & $\begin{array}{c}\text { Percentage of } \\
\text { participants }\end{array}$ & Mean \pm Std & Median \\
\hline 0 & 21 & $1.9 \%$ & \multirow{12}{*}{$6.4181 \pm 2.47159$} & \multirow{12}{*}{7} \\
\hline 1 & 17 & $1.5 \%$ & & \\
\hline 2 & 51 & $4.5 \%$ & & \\
\hline 3 & 72 & $6.4 \%$ & & \\
\hline 4 & 104 & $9.2 \%$ & & \\
\hline 5 & 126 & $11.2 \%$ & & \\
\hline 6 & 101 & $8.9 \%$ & & \\
\hline 7 & 172 & $15.2 \%$ & & \\
\hline 8 & 227 & $20.1 \%$ & & \\
\hline 9 & 141 & $12.5 \%$ & & \\
\hline 10 & 97 & $8.6 \%$ & & \\
\hline Total & 1129 & $100 \%$ & & \\
\hline
\end{tabular}

\section{Discussion}

The concept of beauty in appearance varies between individuals in a population [15,24]. We found that $61.1 \%$ in our study were satisfied with their smile, which was higher than previous studies performed in Al-Jouf, Saudi Arabia (50\%) [23] and other countries, such as Malaysia (47.2\%) [15] and Turkey (57.3\%) [21]. This value is comparable to studies performed in
Palestine (65\%) [25] and Jordan (65.5\%) [4], while it is lower than studies performed in the UK (76\%) [26] and Nigeria (79.4\%) [27].

Attitudes toward dental appearance are influenced by cultural factors and individual preferences, which also differ among them and are changing over time [13]. Prior studies have suggested that older people (age 55 years and above) are 
more likely than younger people to be satisfied with their dental appearance $[21,26]$, indicating that the appearance of their teeth is not as important to older than to younger individuals [18]. However, Tin-Oo et al. [15] found that age is not associated with satisfaction with the smile, suggesting that dental appearance is becoming important in both older and younger adults, which is in accordance with this study [15]. This could be due to the strong impact of the media, which makes men and women of all ages want to look younger and more beautiful [21].

It is known that females are more fascinated and more critical in judging their dental appearance than males $[15,18,28]$. Previous results have demonstrated that females express greater dissatisfaction with their dental appearance and tooth color [2]. This is in contrast with a study performed in Sweden, which revealed that males consider dental appearance as more important than females [29], while this study reported that there were no significant differences, which is in accordance with other studies [21,22].

Perception of tooth color is an intricate phenomenon that is affected by many factors, including lighting conditions, the optical properties of teeth (translucency, opacity, scattering of light, and surface gloss) and the viewer's visual experience [30]. We found that most participants (63.6\%) were dissatisfied with the color of their teeth, which is in accordance with studies performed in AlJouf, Saudi Arabia (65.9\%); Malaysia (56.2\%) and Turkey (55.1\%), which indicates that the tooth color is a critical factor influencing satisfaction with smile appearance $[13,15,21,23]$. In agreement with previous results, we found that dissatisfaction with the tooth color may be the main reason for smile dissatisfaction. It was then further found in this study that tooth whitening is the esthetic treatment most desired by participants, a finding that is similar to studies performed in Aljouf, Saudi Arabia [23]; Malaysia [15] and India [20,24]. By contrast, another study performed in Germany by Höfel et al. [31] reported that perception of facial attractiveness was not related to tooth color, indicating that satisfaction with dental appearance may not positively correlate with facial attractiveness [31].

Poor tooth alignment and crowding are among the most common malocclusion traits reported in the literature 32-34. In agreement with other studies, tooth crowding, malalignment, and teeth protrusion are all factors affecting participants' satisfaction with their smile appearance $[15,21,23]$. The presence of these factors may cause the participants to view their teeth as less attractive. This was supported by participants' the desire for orthodontic treatment to improve the smile. Of note, one study performed by Tin-Oo et al. showed that tooth malalignment does not affect the patient satisfaction with the general appearance, which contradicts the results of this study [15]. There is a significant association between tooth color and malalignment, which indicates dental practitioners, might want to consider the need for tooth whitening when planning orthodontic treatment. Karamouzos A et al. stated that 'the color of natural teeth is changed in various ways after fixed orthodontic treatment ' [35], which supports to our recommendation to perform tooth whitening after orthodontic treatment.

The presence of dental caries, fractures or non-esthetic filling in the anterior teeth will undoubtedly influence the appearance of teeth, which probably leads to smile dissatisfaction $[15,24]$. Although most of the participants in this study reported they did not have any of these conditions, some were dissatisfied, which could be due to other factors that affect smile satisfaction.

Beautiful smiles are created by three main parameters, which are the dentition, gingiva, and lips [36]. An excessive gingival display is one of the most common features affecting the smile [37]. In this study, $21.7 \%$ of the participants were dissatisfied with the amount of gingival display when smiling, and $26.1 \%$ were not satisfied with the color of their gingiva, which shows that gingival health and display are important aspects of a pleasing smile. Different samples, individual characteristics, and cultural backgrounds might explain the controversy regarding satisfaction with dental appearance [23]

\section{Conclusion}

High levels of dissatisfaction with smile appearance and a higher level of tooth color dissatisfaction were reported in this study, which affected the desire for teeth whitening. These results provide useful information about the potential needs for dental treatment, particularly esthetic treatments, including teeth whitening, orthodontic treatment and veneers. Moreover, understanding patients' perceptions of their smiles is an important aspect of good patient management, which may help dentists provide adequate and appropriate treatment plans to achieve a high level of patient satisfaction.

\section{References}

1. Jenny J, Proshek JM (1986) Visibility and prestige of occupations and the importance of dental appearance. J Can Dent Assoc 52(12): 987989.

2. Samorodnitzky-Naveh GR, Geiger SB, Levin L (2007) Patients satisfaction with dental esthetics. J Am Dent Assoc 138(6): 805-808.

3. Alkhatib MN, Holt R, Bedi R (2004) Prevalence of self-assessed tooth discolouration in the United Kingdom. J Dent 32(7): 561-566.

4. Karasneh J, Al-Omiri MK, Al-Hamad KQ, Al Quran FA (2009) Relationship between patients' oral health-related quality of life, satisfaction with dentition, and personality profiles. J Contemp Dent Pract 10(6): E049-E056.

5. Newton JT, Prabhu N, Robinson PG (2003) The impact of dental appearance on the appraisal of personal characteristics. Int J Prosthodont 16(4): 429-434.

6. Davis LG, Ashworth PD, Spriggs LS (1998) Psychological effects of aesthetic dental treatment. J Dent 26(7): 547-554.

7. Wolfart S QA, Freitag S, Kropp P, Gerber WD, Kern M (2006) General well-being as an important co-factor of self assessment of dental appearance. Int J Prosthodont 19(5): 449-454.

8. Judith H, Langlois LAR (1990) Attractive Faces Are Only Average. Journal of the Association for Psychological Science 1(2): 115-121. 
9. Tufekci E, Jahangiri A, Lindauer SJ (2008) Perception of profile among laypeople, dental students and orthodontic patients. Angle Orthod 78(6): 983-987.

10. Helm S, Kreiborg S, Solow B (1985) Psychosocial implications of malocclusion: a 15-year follow-up study in 30-year-old Danes. Am J Orthod 87(2): 110-118.

11. Espeland LV, Stenvik A (1991) Perception of personal dental appearance in young adults: relationship between occlusion, awareness, and satisfaction. Am J Orthod Dentofacial Orthop 100(3): 234-241.

12. Kershaw S, Newton JT, Williams DM (2008) The influence of tooth colour on the perceptions of personal characteristics among female dental patients: comparisons of unmodified, decayed and 'whitened' teeth. Br Dent J 204(5): E9.

13. Qualtrough AJ, Burke FJ (1994) A look at dental esthetics. Quintessence Int 25(1): 7-14.

14. Van der Geld P, Oosterveld P, Van Heck G, Kuijpers-Jagtman AM (2007) Smile attractiveness. Self-perception and influence on personality. Angle Orthod 77(5): 759-765.

15. Tin-Oo MM, Saddki N, Hassan N (2011) Factors influencing patient satisfaction with dental appearance and treatments they desire to improve aesthetics. BMC Oral Health 11: 6.

16. Duarte S, Schnider P, Lorezon AP (2008) The importance of width/ length ratios of maxillary anterior permanent teeth in esthetic rehabilitation. Eur J Esthet Dent 3(3): 224-234.

17. Desai S, Upadhyay M, Nanda R (2009) Dynamic smile analysis: changes with age. Am J Orthod Dentofacial Orthop 136(3): 310.

18. Vallittu PK, Vallittu AS, Lassila VP (1996) Dental aesthetics--a survey of attitudes in different groups of patients. J Dent 24(5): 335-338.

19. Ahmed B, Gilthorpe MS, Bedi R (2001) Agreement between normative and perceived orthodontic need amongst deprived multiethnic school children in London. Clin Orthod Res 4(2): 65-71.

20. Afroz S, Rathi S, Rajput G, Rahman SA (2013) Dental esthetics and its impact on psycho-social well-being and dental self confidence: a campus based survey of north Indian university students. J Indian Prosthodont Soc 13(4): 455-460.

21. Akarslan ZZ, Sadik B, Erten H, Karabulut E (2009) Dental esthetic satisfaction, received and desired dental treatments for improvement of esthetics. Indian J Dent Res 20(2): 195-200.

22. Xiao J, Zhu WC, Zhang B, Li JY, Xu X, et al. (2007) The prevalence of tooth discolouration and the self-satisfaction with tooth colour in a Chinese urban population. J Oral Rehabil 34(5): 351-360.

23. Al-Zarea BK (2013) Satisfaction with appearance and the desired treatment to improve aesthetics. Int J Dent 2013: 912368.
24. Rupal J Shah, Farheen G Malek, Preeti Agarwal (2014) A Study of Patient Satisfaction with Maxillary Anterior Teeth Restorations and Desirable Esthetic Treatment Options. Journal of Dental and Medical Sciences 13(10): 79-86.

25. Younis A A-OM, Hantash RO, Alrabab'Ah M, Dar-Odeh N, Abu Hammad O, et al. (2012) Relationship between dental impacts on daily living, satisfaction with the dentition and personality profiles among a Palestinian population. Odontostomatol Trop 35(138): 21-30.

26. Alkhatib MN, Holt R, Bedi R (2005) Age and perception of dental appearance and tooth colour. Gerodontology 22(1): 32-36.

27.Azodo C, Ogbomo A (2014) Self-Evaluated Dental Appearance Satisfaction among Young Adults. Ann Med Health Sci Res 4(4): 603607.

28. Hassel AJ, Wegener I, Rolko C, Nitschke I (2008) Self-rating of satisfaction with dental appearance in an elderly German population. Int Dent J 58(2): 98-102.

29. Carlsson G JA, Johansson A, Ordell S, Ekbäck G, Unell L (2008) Attitudes toward dental appearance in 50- and 60-Year-old subjects living in Sweden. J Esthet Restor Dent 20(1): 46-55.

30. Joiner A (2004) Tooth colour: a review of the literature. J Dent 32 (Suppl 1): 3-12.

31. Hofel L, Lange M, Jacobsen T (2007) Beauty and the teeth: perception of tooth color and its influence on the overall judgment of facial attractiveness. Int J Periodontics Restorative Dent 27(4): 349-357.

32. Jonsson T, Arnlaugsson S, Karlsson K, Ragnarsson B, Arnarson E, et al. (2007) Orthodontic treatment experience and prevalence of malocclusion traits in an Icelandic adult population. Am J Orthod Dentofacial Orthop 131(1): 8 .

33. Onyeaso CO (2004) Prevalence of malocclusion among adolescents in Ibadan, Nigeria. Am J Orthod Dentofacial Orthop 126(5): 604-607.

34. Borzabadi-Farahani A, Borzabadi-Farahani A, Eslamipour F (2009) Malocclusion and occlusal traits in an urban Iranian population. An epidemiological study of 11- to 14-year-old children. Eur J Orthod 31(5): 477-484

35. Karamouzos A, Athanasiou AE, Papadopoulos MA, Kolokithas G (2010) Tooth-color assessment after orthodontic treatment: a prospective clinical trial. Am J Orthod Dentofacial Orthop 138(5): 537.

36. Mahesh Narayanan SL, Susil M Erali, Erali SM, Al Zainab Fathima, Gopinath PV et al. (2015) Gummy Smile Correction with Diode Laser: Two Case Reports. J Int Oral Health 7(Suppl 2): 89-91.

37. Santhanakrishnan Muthukumar, Natarajan S, Seenivasan Madhankumar, Jayakrishnakumar Sampathkumar (2015) Lip repositioning surgery for correction of excessive gingival display. J Pharm Bioallied Sci 7(Suppl 2): S794-S796.

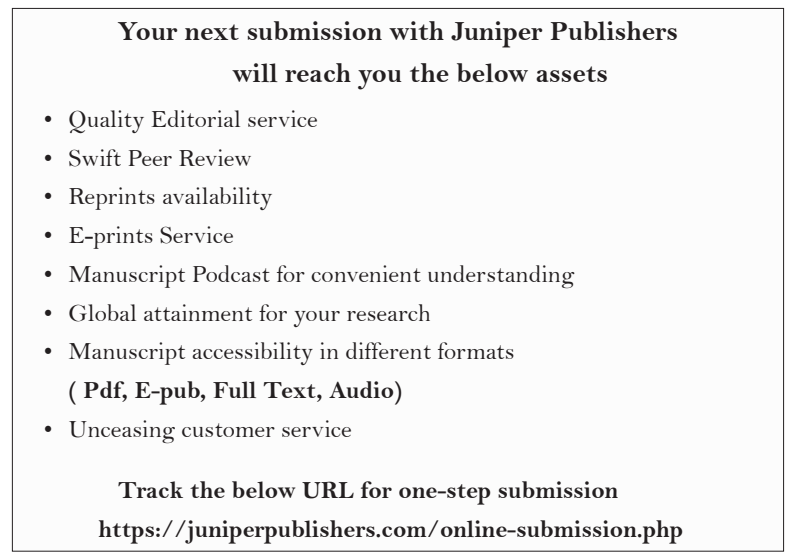

